\title{
IS ORGANIZATIONAL DESIGN A HUMAN-CENTERED DESIGN PRACTICE?
}

\author{
Auernhammer, Jan Michel Kurt; Leifer, Larry \\ Stanford University
}

\begin{abstract}
In recent years design has had a renaissance in business and management research and practice. Several authors have discussed if management is a design practice and how far design ought to go to design behaviors. This article discusses, evaluates and explores organizational design as a human-centered design practice. Relevant theoretical concepts of organizational theory, design approaches and practices are discussed to evaluate gaps in management practices and potential opportunities for design practice. The study collected and analyzed data from two organizations. The researched revealed several propositions, which provide insights of the usefulness, appropriateness and value of a human-centered design practice to organizational design.
\end{abstract}

Keywords: Organizational Design, Human-centered Design, Design practice, Design management, Organizational processes

\section{Contact:}

Auernhammer, Jan Michel Kurt

Stanford University

Mechanical Engineering

United States of America

jan.auernhammer@stanford.edu 


\section{INTRODUCTION}

Buchanan (2015) emphasized that designers should design the systems such as organizations they are part of. This idea of managing as designing has been discussed by several scholars (Boland and Collopy, 2004). Traditionally, organizational design has been a strategic management practice. Strategy is concerned with converting a problematic situation of an organization into a preferred situation by reorganizing and reallocating resources to increase business and financial performance. Simon (1969) stated that occupations that engage in converting actual to preferred situations are concerned with design. From this point of view, management is concerned with design. Schön (1983) identified similar tendencies, the thinking of policies, institutions, and behaviors as objects of design. He questioned how far in this direction the design field ought to go. However, management and design practices influence human actions in everyday life and therefore organizational performance. Current management practices focus on aligning organizational structures, processes, reward systems, and human resources to determine human activities towards strategic business objectives (e.g. Galbraith, 2014). Weick (2004) criticizes the current thinking about organizational design as it creates obstacles and limitations. He states as long as managers and theorists keep the pervasive scenario of machinemetaphors and mechanistic assumptions onto events, they create static clockworks and control constrains. Similar, Mintzberg (2005) stated that business schools have not explicitly recognized designing skills even though they make prominent use of expressions such as "organizational design" and such designing is taught based on analysis. Therefore, the main question arises, what are the design-based practices that allow to design organizations beyond the mechanistic assumptions and analytical approaches? This research investigates the practice of designing organizations based on creative, action-based learning and a human-centered approach to go beyond analytical practices of machine-metaphors. The paper outlines this organizational design approach and presents several propositions of this practice.

\section{BACKGROUND}

Designing organizations incorporates its own unique complexity, which requires its own unique practices like any specific design domain. Any particular practice and approach to organizational design is based on underlying theories and concepts. This section will discuss the several approaches of designing organizations and related challenges. It concludes by outlining a design-based practice that centers the human in its approach.

\subsection{What are the different approaches to designing organizations?}

Researchers have investigated strategy making, the practice and process of designing organizations (e.g. Huff and Reger, 1987, Hutzschenreuter and Kleindienst, 2006). To provide a structure to the discussion of the different strategy making approaches, Mintzberg's $(1987,2007)$ distinction of plan, ploy, pattern, position, and perspective is used. Plan, pattern and perspective are relevant for designing organizations, while ploy and position are more concerned with strategic moves than design considerations (Mintzberg, 1987, 2007). The practice approaches of plan, pattern and perspective can be linked to the three main domains of structure, behavior and cognition in organizational theory.

\subsubsection{Planning approach to organizational design}

Strategy making as a planning exercise incorporates the practices of designing and developing a unified, comprehensive and integrated plan to ensure that the core business objectives of the organization are achieved (Mintzberg, 1987, 2007). The conscious and purposeful formulation of the strategic plan is made in advance of action and implementation. This includes configuring and integrating several different units, resources and systems of the organization (Miles et al., 1978). The abstract conceptualization of the organizational reconfiguration is based on analyzing current situations and utilizing generic theories and models such as the star model by Galbraith (2014) or 7-S model by Waterman et al. (1980). The implementation of the conceptual design requires management practices as people are managed to "fit" to the organizational goals, structure and design (Burton et al., 2015). Behavior is enforced by controlling constrains and defined roles and responsibilities. This approach can be linked to the structural view in organizational theory. 


\subsubsection{Pattern approach to organizational design}

Strategy making from the pattern-view is seen as consistency in patterns of actions and behavior whether or not intended (Mintzberg, 1987, 2007). This view allows to understand not only strategy and organizational design as a deliberate activity, but as emerging behavior (Mintzberg, 1978, 1979, 2007). Such patterns of activities are organizational routines which are the micro-foundations of organizational capabilities (Felin et al., 2015, Abell et al., 2008). Organizational design practice in the pattern view requires making sense of everyday events within the organization. Sensemaking tries to answer the questions of how something comes to be an event for organizational members, what does this event mean and what is the story within the context of everyday life (Weick et al., 2005). Organizational design becomes an everyday activity. Leadership practices are required to understand and influence people to enact specific patterns of activities within the organizations. The organizational design is constituted by reoccurring activities and can be linked to the behavioral view in organizational theory.

\subsubsection{Perspective approach to organizational design}

The last view provides an understanding of the organizational design as a collective perspective, ideology or Weltanschauung. Strategies and organizational designs are abstract concepts in the minds of people, which lead to distinct ways of acting and responding (Mintzberg, 1987). Organizational design practices require a constant (re-)framing of shared perspectives and recognizing gaps in shared perception and actual results. These collective or organizational learning practices have been elaborated by Argyris (1999), Argyris and Schön (1996) as well as Senge (2006). Organizational design practice from this view focuses on designing organizations to enable collective learning and can be linked to the learning and knowledge management approach in organizational theory.

The three different approaches of plan, pattern and perspective provide an overview of how organizational design can be approached. However, organizations are a combination of structure, behavior and worldviews as planned structures, processes, roles and responsibilities guide peoples' activities and peoples' cultivated patterns of behavior and activities in combination with their shared world views produce the everyday organizational life, performance and design. This makes the design a complex and dynamic challenge, similar to wicked problems as outlined by Rittel and Webber (1973).

\subsection{What are the challenges in organizational design and change?}

Organizations are complex social units of people. This social unit consists of a multi-level complexity, namely individuals, groups, and organization (e.g. Robbins and Judge, 2013). Individual and team activities produce the organizational system and in turn this system enables or constrains peoples' activities, behavior and learning. This is the recursive interaction between agency and structure as outlined by Giddens (1984). It is often described as the top-down and bottom-up process in organizational change.

\subsubsection{Challenges of a top-down design and organizational change}

A top-down approach of enforcing change through a sense of urgency has been described by Kotter (1995, 2007). Urgency for change can create stress and uncertainty. Such approaches may be appropriate in a crisis. In contrast, developing organizational capabilities require a learning environment and is based on peoples' motivation and interest. Another challenge relates to the complexity that organizational design is dependent on the product architecture which is embedded in organizational communication patterns (Sosa et al., 2004). A top-down approach often decomposes the product architecture into different organizational units. Modularization in product and organizational architecture allows flexibility (Sosa et al., 2004). However, it doesn't allow organizational transformation and innovation as permanent structures can be highly risky to change. Transformation can be designed by developing dynamic capabilities within the organization (Teece et al., 1997). In the context of organizational re-design for capabilities such as self-organization and/or innovation the top-down design approach is counterproductive. Pre-organization for self-organization is a paradox, and innovation requires discovering new ways of doing and organizing rather than preplanning and implementing a design based on existing products. In such a design approach, innovation is possible by structurally separating the innovation unit from the existing organization (e.g. Tushman 
and O'Reilly, 2006). Innovation and transformation require emergent patterns of activities, communication, behavior and learning.

\subsubsection{Challenges of a bottom-up design and organizational change}

A bottom-up approach is often not a designed process but a collective emergent process. Patterns of activities, behavior and interacting worldviews that are cultivated and shared produce the way of working within the organization. This constitutes the culture of the organization (Schein and Schein, 2016). This has been linked to organizational routines and capabilities as discussed by Eisenhardt and Martin (2000) and to organizational identity and competencies as described by Fiol (1991). Changes in the patterns of activities and worldviews drive the evolution of the organization (Nelson and Winter, 1982). The main challenge is that there is not a well-developed practice that allows to design this emergence in organizations. For example, emergence by designs has been described as incorporating specific hiring and training practices, created a small company collegial culture, developed reliable software processes and implemented a companywide information system (Garud et al., 2006). Such design examples provide retrospectively a successful organizational design for a specific challenge. However, it does not provide an approach or practice to design organizational emergence. So, what are the potential organizational design practices that can design emergent and reoccurring human patterns of change and organizational evolution?

\subsection{How can organizations be designed creatively and human-centered?}

Buchanan (2007) argues that design could offer a new way to understand and practice management, leading to more human-centered organizations. Human-centered design is traditionally applied in practice such as communication, product, service and interaction design to design human experiences (e.g. Diller et al., 2005, Norman, 2011). This design practice incorporates activities such as ethnographic observations, framing and formulating of problem situations, visualizing alternative situations and rapid prototyping to design human experiences (e.g. Beckman and Barry, 2007, Leifer and Steinert, 2011).

\subsubsection{Designing for the problem situation and peoples' needs within the organization}

Understanding human context through anthropology and ethnography allows to identify current needs and problem situations (Patnaik and Becker, 2010, Otto and Smith, 2013). This has been practiced in organizational context since the 1930s and is a fast-growing academic field (Otto and Smith, 2013). Ethnography allows to understand social context through inquiry of immediate situational surroundings and the human beings involved, while design adds the practices to actively engage and collaborate in the formulation of interventions to establish preferred situations (Otto and Smith, 2013). Utilizing this practice allows to understand reoccurring patterns of activities, behavior and worldviews as well as the context in which these patterns emerge within the organization. This allows to identify and frame human challenges within the organization.

\subsubsection{Creative organizational design}

Dorst (2015) investigated how designers create these frames. He noted that designers do not only frame the problem situation, they frame alternative solutions and explore them to solve open, complex, dynamic and networked problems. These design activities are often supported by visual thinking. Visual thinking allows to perceive, abstract, imagine and express situations as well as explore and communicate alternative situations (McKim, 1980). These visual design activities allow to imagine and generate new organizational design solutions focused on the challenge at hand rather than searching, analyzing and implementing generic strategies.

\subsubsection{Action-based learning in organizational design}

Abstract models of alternative situations and experiences can be produced, validated and improved through prototypes. The idea of experimentation in organization and operation management has been discussed in the organizational learning domain (Levitt and March, 1988, Bakken et al., 1992). Designers approach the organizational design challenge by designing and prototyping the physical space to change behavior (Coughlan et al., 2007). However, organizational prototyping may go beyond the physical and can prototype situations including interactions, activities and routines of 
learning within organizations. Thus, allowing fast and direct experiential learning through action about the organizational design solution.

\subsubsection{Design pattern language}

Another important aspect that needs to be taken into account is the interrelated and multi-level organizational complexity as discussed above. Alexander et al. (1977) and Alexander (1979) outlined a design pattern language in architecture to design towns, buildings, constructions for a timeless way of building and to produce what Alexander calls the quality without a name, the moments humans are most alive. A pattern language allows to design patterns on multiple levels, which allows to design for multi-level complexity. This pattern language has been applied to capture and communicate human activities as well as to understand organizational designs (e.g. Rising, 1998, Auernhammer, 2012, Iba, 2010 , 2014). Capturing both the problem situation and the solution (preferred situation) that contributes to the organizational capability in design patterns allows to offer, judge and reproduce this alternative human situation within the organization. If the solution is valuable to people, the likelihood that it is cultivated and reproduced increases.

These several outlined activities provide the basis for the design practices for designing organizations in this research. They have been applied independently in organizations. However, there is no cohesive design practice to design organizations. Therefore, the research investigates: What constitutes a cohesive organizational design practice that allows designing organizational capabilities such as self-organization and innovation?

\section{METHODOLOGY}

This research is an ongoing longitudinal research in collaboration with two large organizations in Germany and Japan in the mobility and media industry. The findings presented in this paper resulted from data collected within one-year investigation in the first company and two-month investigation in the second. Both organizations aim to design their organizations towards capabilities such as selforganizations and digital business innovation. Both research projects follow the same research approach as outlined in this section.

\subsection{How to research a non-common practice?}

Organizational design as a human-centered design practice is not a common practice that can be observed and described. Therefore, the research is designed to enable design teams within the organizations to exercise and develop this practice. This allows future-orientated design practice research as advocated by Dorst (2008) in a systematic manner by ethnographically observing the established practices and their outputs and results within the organization. It allows to observe the value and applicability of such practices and iteratively develop it as illustrated in Figure 1.

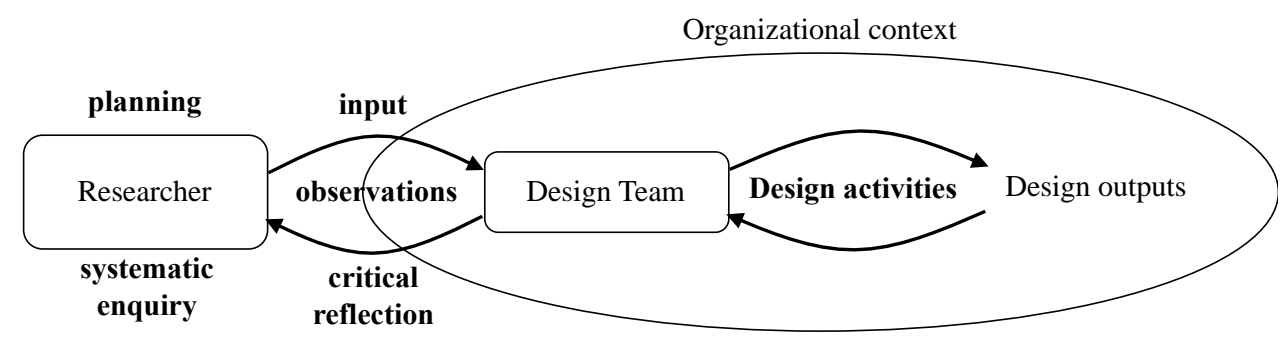

Figure 1. Establishment of design practice and observation of its value and applicability

\subsection{How to examine, analyze and evaluate the organizational design practices?}

The established design activities and outputs were observed within organizational context and analyzed and evaluated to reveal which activities enabled changing the current situation to a preferred one.

\subsubsection{Data collection}

Data was collected through observation, note and photo taking, audio and video recording of the organizational design teams' conversations, activities and outputs within input, and action and 
reflection sessions. Additionally, produced documents have been collected from the several activities. Teams have been observed in week long design sessions and interviewed in weekly reflection sessions via phone. This allowed to examine specific design team activities and related outputs as well as the overall progress and linkage of the different design activities.

Several design activities allowed to capture the organizational context. For example, one design team accomplished more than eighty conversations with people about their everyday organizational life experience. Thus, allowed to understand current organizational context and identified peoples' reoccurring problem situations and needs. Another example is that several design interventions have been experimented in small team settings to learn and get feedback. These insights allowed to observe the design activities as well as the context and influence within the organization.

\subsubsection{Data analysis and evaluation}

The collected data was analyzed to examine the input, actual activities, outputs and influences. The several design activities were examined to understand their usefulness or value in changing peoples' problem situations towards preferred situations. The data was analyzed through open, axial and selective coding as outlined by Corbin and Strauss (2014) and explanatory qualitative analysis as outlined by Miles et al. (2013). Triangulation of the analysis of field notes, audio and video recordings, documents and photo images provided a coherent analysis.

The data analysis revealed several chains of design activity from input, practice of activities to influence within the organizations. These are summarized in several propositions. As this is ongoing research the paper presents selected propositions which provide insights of what design activities constitute organizational designing.

\section{FINDINGS - WHAT CONSTITUTES ORGANIZATIONAL DESIGNING?}

The findings revealed several propositions of value of the design-based activities for designing organizations which are outlined in this section. The first proposition indicates the usefulness of focusing on people within the organizations through design ethnography.

\section{Proposition 1: Design ethnography reveals peoples' problem situations and needs that drive motivation and behavior enabling the development of organizational capabilities}

Design ethnography was practiced in order to understand the experience of people within the organization and revealed peoples' needs and problem situations that prevented people to accomplish desired capabilities such as self-organized working and innovation. For example, eight reoccurring problem situations such as "purpose of change", "no team collaboration", "change of structure and no change of behavior" and "no open feedback" have been identified by the design team. These observed problem situations included situational and organizational context, which provided an explanation of why the situation occurred and what has been cultivated within the organization that produced its reoccurrence. For example, one of the predominant reasons that no team collaboration reoccurred was because tasks were allocated to individuals in meetings and by supervisors. It established a way of working in which individuals worked independently to execute tasks rather than collaboratively accomplish tasks. This contextual problem framing allowed to understand the systematic and cultivated problem situations in more detail that prevented teams to self-organize within the organization. The detailed understanding allowed the designers to creatively approach this contextspecific problem situation rather than implement generic solutions and methodologies.

\section{Proposition 2: Design ethnography allows to capture and enable feedback about cultural implications of management decisions}

Another interesting proposition is the learning about behavioral and motivational impacts of strategic management decision through ethnography. For example, the identified and synthesized problem situation within organizational context and peoples' needs from the many conversations were presented to top-management. This allowed to provide feedback about the impacts of strategic decision making on people. A specific strategic management choice has resulted in optimizing performance within teams and resulted in silo building between teams and therefore reduced interteam collaboration. This feedback from peoples' experiences allowed to understand the behavioral and motivational impacts within the organization. This organizational learning through feedback from design ethnography activities is illustrated in Figure 2. 


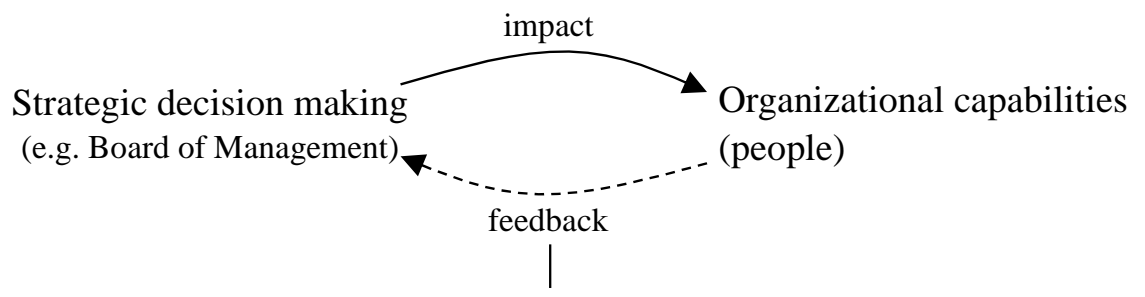

Synthesized ethnographic research allows to

learn about impact on people (e.g. behavior)

\section{Figure 2. Feedback about peoples' situation affected by strategic decisions}

As shown in Figure 2, an organizational design team can operate as a learning mechanism between strategic management decision making and its impact on people and organizational capabilities.

\section{Proposition 3: Problem situations are not isolated problems and cannot be solved in isolation}

Organizational design challenges are highly interconnected problems. Solving one problem situation may result in producing or enforcing another problem situation. Such wicked problems may never be fully understood it in its entire complexity. An approach to identify, isolate and prioritize a problem may not lead to improvements in the organizations. For example, the focus on redesigning the evaluation of teams with the intent to emphasize on team performance and self-organization within teams solved one problem situation. However, at the same time it influenced the behavior of teams resulting in self-organizing within teams and not between teams. Understanding these interrelations between one problem situation and another by combining different organizational design patterns allowed to understand and tackle these interconnected and complex issues.

\section{Proposition 4: Organizational prototyping allows rapid learning to discover design requirements for preferred organizational design solutions}

Organizational prototyping enabled to validate the identified problem situations as well as revealed design requirements. For example, the design team developed a prototype to quickly identify why people are not collaborating. An exercise was designed that required to accomplish a task that represents current task allocation in teams. The exercise was performed several times and each time the prototype was changed. In one iteration it was uncovered that how tasks are communicated influences peoples' collaborative behavior. By changing the communication of the task another requirement was uncovered. If the task includes a competitive situation (someone can win) peoples' collaborative behavior was influenced. Such action based-learning through prototyping allowed to iteratively discover how the desired situation should be within the organizational context. It also allowed to uncover the problem situation in more detail. Organizational prototyping can be used for evaluating assumptions and validating identified problem situations. This problem and solution exploration prototyping enabled the designer to overcome potential biases and uncovered design requirements necessary to enable desired organizational capabilities such as collaboration.

\section{Proposition 5: Organizational design is about experience the design}

Another proposition has been revealed through the comparison of strategic practices and organizational designing. Strategy practices incorporated the modelling and communication of new organizational designs. For example, collaboration models have been communicated through various channels to people. Implementation consisted of communicating and explaining the new design, the new way of working. This had several limitations as people may interpret the communicated plan very differently or were overloaded with information. In contrast, the design-based practices focused on creating experiential and observable prototypes. This experience of the new design enables them to judge it and provide feedback. It allowed to iteratively learn through observation and feedback to improve the design. It linked concept design, action through prototyping and learning through reflection closely together rather than separating strategy formulation and implementation through communicating organizational concepts.

\section{Proposition 6: Organizational design is based on cultivated and reoccurring situations}

Organization is based upon shared and cultivated patterns of activities, behavior, worldviews and norms. Designers need to consciously recognize and visualize these patterns to re-design them to enable people towards the desired organizational capability. Actively changing these patterns can be 
explored and experimented by prototyping as discussed above. For an organization wide impact this designed new situation needs to be replicated or cultivated. For example, shared stories and rumors within the organization have created uncertainty and concerns within the organizational transformation. A prototype was designed to provide a safe space to openly discuss shared stories and narratives to reduce the uncertainty and concerns. This purposefully designed new situation within the organization is effective in a specific problem situation and can be replicated by others when having a similar problem. Such designed desired situations can be communicated through design patterns as it includes the problem situation and context and the solution with an instruction to replicate it. Designing and replicating organizational design patterns allows to re-design emergence within organizations.

As the several propositions indicate, organizational designing is constituted by the following activities and practices. A deep engagement with people reveals and provides an understanding of their problem situation and needs. Communicating the synthesized insight allows to influence decision making to take peoples' situations into account. Approaching the problem situations as interconnected problems allows to avoid optimizing for one problem and triggering another problem. Organizational prototypes that can be experienced by people permits rapid learning about the desired situation. Lastly, making the desired situation replicable allows to scale the design solution within the organization.

\section{CONTRIBUTION AND IMPLICATIONS}

The practice of organizational designing offers a problem-focused, creative, action-based learning that centers people in the design approach. It offers a different approach to the machine-metaphors and mechanistic assumptions as criticized by Weick (2004). Organizational designs need to solve the problem situations that prevent people from accomplishing capabilities such as self-organization and innovation. Furthermore, organizational designs need to be based on peoples' needs. People only replicate and cultivate the designs when they are valuable to them. This differs from a top-down, organization-wide formulation and implementation activity or change management as outlined by Kotter $(1995,2007)$. The organizational design needs to solve a problem situation, must be based on peoples' needs and accomplish desired organizational capabilities as illustrated in Figure 3. Thus, making organizational designing a practice of dynamic capability as outlined by Teece (2007).

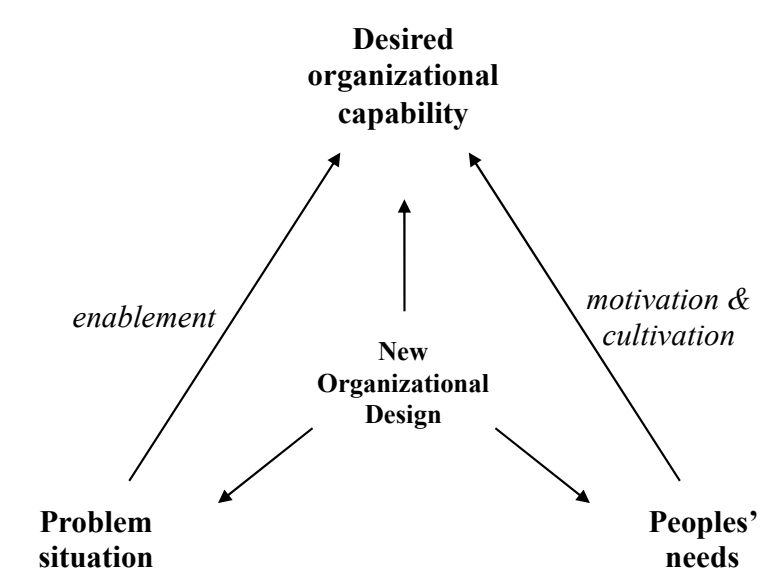

Figure 3. Designing organizational capabilities by solving problems \& fulfilling peoples' needs

\subsection{What are the implications for research?}

There is a need to research and develop practices that close the gap between peoples' everyday routines, experiences, organizational capabilities and business performance. Linking performance to design patterns of peoples' activities may provide a new insightful way of understanding organizational capabilities and performance. Future research may investigate the design practices that allow to combine approaches to design structure, behavior and worldview and their interrelations in more meaningful ways for people. Weick (2004) indicated that the organizational structure should have as little design as possible to allow organic, emergent, social structure to develop. Future research can investigate the interrelation of different structures, behaviors and worldviews through an organizational design pattern language lens and to investigate different types of designs such as loose 
coupling. Understanding the interrelations between meaningful everyday experiences and high organizational and business performance and how it can be designed may reveal a better understanding of the development of organizational capabilities.

\subsection{What are the implications for practice?}

The organizational designing practice as outlined in this paper can make organization more humancentered. It can become a distinct design discipline to support people in developing meaningful routines and experiences and developing organizational capabilities. An independent or neutral design team with members from different parts of the organization may be able to solve organizational problem situations as managers, leaders and employees are part of the multi-perspective problem situation. Another important aspect is organizational designs are offered, experienced and iteratively developed, they are not dictated or produced by constraints. It requires understanding and designing for multiple stakeholders as the design needs to be valuable to be cultivated. These design-based practices as outlined in this paper provide a conscious and active approach to continuously and iteratively design organizational capabilities and evolution.

\section{REFERENCES}

Abell, P., Felin, T. and Foss, N. (2008), "Building micro-foundations for the routines, capabilities, and performance links". Managerial and Decision Economics, Vol. 29, pp. 489-502.

Alexander, C. (1979), The Timeless Way of Building, Oxford University Press.

Alexander, C., Ishikawa, S. and Silverstein, M. (1977), A Pattern Language: Towns, Buildings, Construction, Oxford University Press.

Argyris, C. (1999), On Organizational Learning, Wiley.

Argyris, C. and Schön, D. A. (1996), Organizational Learning II: Theory, Method, and Practice, AddisonWesley Publishing Company.

Auernhammer, J. M. (2012), “Autopoietic organisation of knowledge, creativity and innovation: a case study of the automotive manufacturer Daimler AG". PhD, University, Edinburgh Napier.

Bakken, B., Gould, J. and Kim, D. (1992), "Experimentation in learning organizations - A management flight simulator approach". European Journal of Operational Research, Vol. 59, pp. 167-182.

Beckman, S. L. and Barry, M. (2007), "Innovation as a learning process: Embedding design thinking". California Management Review, Vol. 50, pp. 25-+.

Boland, R. J. and Collopy, F. (2004), Managing as designing, Stanford Business Books, Stanford, CA.

Buchanan, R. (2007), "Introduction: Design and Organizational Change". Design Issues, Vol. 24, pp. 2-9.

Buchanan, R. (2015), "Worlds in the Making: Design, Management, and the Reform of Organizational Culture". She Ji: The Journal of Design, Economics, and Innovation, Vol. 1, pp. 5-21.

Burton, R. M., Obel, B. and Håkonsson, D. D. (2015), Organizational Design: A Step-by-Step Approach, Cambridge University Press.

Corbin, J. and Strauss, A. (2014), Basics of Qualitative Research: Techniques and Procedures for Developing Grounded Theory, SAGE Publications.

Coughlan, P., Suri, J. F. and Canales, K. (2007), "Prototypes as (Design) tools for behavioral and organizational change: a design-based approach to help organizations change work behaviors". The Journal of Applied Behavioral Science, Vol. 43, pp. 122-134.

Diller, S., Shedroff, N. and Rhea, D. (2005), Making Meaning How Successful Businesses Deliver Meaningful Customer Experiences, New Riders, Berkeley, CA.

Dorst, K. (2008), “Design research: a revolution-waiting-to-happen”. Design Studies, Vol. 29, pp. 4-11.

Dorst, K. (2015), Frame Innovation: Create New Thinking by Design, MIT Press.

Eisenhardt, K. M. and Martin, J. A. (2000), "Dynamic capabilities: What are they?" Strategic Management Journal, Vol. 21, pp. 1105-1121.

Felin, T., Foss, N. J. and Ployhart, R. E. (2015), "The microfoundations movement in strategy and organization theory". Academy of Management Annals, Vol. 9, pp. 575-632.

Fiol, C. M. (1991), "Managing culture as a competitive resource: An identity-based view of sustainable competitive advantage". Journal of Management, Vol. 17, pp. 191-211.

Galbraith, J. R. (2014), Designing organizations: an executive guide to strategy, structure, and process.

Garud, R., Kumaraswamy, A. and Sambamurthy, V. (2006), "Emergent by Design: Performance and Transformation at Infosys Technologies". Organization Science, Vol. 17, pp. 277-286.

Giddens, A. (1984), The Constitution of Society: Outline of the Theory of Structuration, University of California Press.

Huff, A. S. and Reger, R. K. (1987), “A review of strategic process research”. Journal of Management, Vol. 13, pp. 211-236. 
Hutzschenreuter, T. and Kleindienst, I. (2006), "Strategy-process research: What have we learned and what is still to be explored". Journal of Management, Vol. 32, pp. 673-720.

Iba, T. (2010), “An autopoietic systems theory for creativity”. 1st Collaborative Innovation Networks Conference - Coins2009, Vol. 2, pp. 6610-6625.

Iba, T. (2014), "Using pattern languages as media for mining, analysing, and visualising experiences". International Journal of Organisational Design and Engineering, Vol. 3, pp. 278-301.

Kotter, J. P. (1995), "Leading change - Why transformation efforts fail”. Harvard Business Review, Vol. 73, pp. 59-67.

Kotter, J. P. (2007), "Leading change - Why transformation efforts fail”. Harvard Business Review, p. 85.

Leifer, L. J. and Steinert, M. (2011), "Dancing with ambiguity: Causality behavior, design thinking, and tripleloop-learning”. Information.Knowledge.Systems Management, Vol. 10, pp. 151-173.

Levitt, B. and March, J. G. (1988), “Organizational learning”. Annual Review of Sociology, Vol. 14, pp. 319340.

Mckim, R. H. (1980), Experiences in Visual Thinking, Brooks/Cole Publishing Company.

Miles, M. B., Huberman, A. M. and Saldana, J. (2013), Qualitative Data Analysis, SAGE Publications.

Miles, R. E., Snow, C. C., Meyer, A. D. and Coleman, H. J., JR. (1978), “Organizational strategy, structure, and process". The Academy of Management Review, p. 3.

Mintzberg, H. (1978), "Patterns in strategy formation”. Management Science, Vol. 24, pp. 934-948.

Mintzberg, H. (1979), “Emerging strategy of direct research”. Administrative Science Quarterly, Vol. 24, pp. $582-589$.

Mintzberg, H. (1987), “The strategy concept.1. 5 ps for strategy”. California Management Review, Vol. 30, pp. 11-24.

Mintzberg, H. (2005), Managers Not MBAs: A Hard Look at the Soft Practice of Managing and Management Development, Berrett-Koehler Publishers, Incorporated.

Mintzberg, H. (2007), Tracking Strategies: Toward a General Theory, Oxford University Press.

Nelson, R. R. and Winter, S. G. (1982), An Evolutionary Theory of Economic Change, Belknap Press of Harvard University Press.

Norman, D. A. (2011), Living with complexity, The MIT Press, Cambridge.

Otto, T. and Smith, R. C. (2013), "Design anthropology: A distinct style of knowing”. In: Gunn, W., Otto, T. and Smith, R. C. (eds.) Design Anthropology: Theory and Practice. Bloomsbury Academic.

Patnaik, D. and Becker, R. (2010), "Needfinding: The why and how of uncovering people's needs". Design Management Journal (Former Series), Vol. 10, pp. 37-43.

Rising, L. (1998), The Patterns Handbook: Techniques, Strategies, and Applications, SIGS.

Rittel, H. W. J. and Webber, M. M. (1973), "Dilemmas in a general theory of planning”. Policy Sciences, Vol. 4, pp. 155-169.

Robbins, S. P. and Judge, T. A. (2013), Organizational Behavior 15th Edition, Pearson.

Schein, E. H. and Schein, P. (2016), Organizational Culture and Leadership, Wiley.

Schön, D. A. (1983), The reflective practitioner: how professionals think in action, Basic Books, New York.

Senge, P. M. (2006), The Fifth Discipline: The Art and Practice of the Learning Organization, Doubleday/Currency.

Simon, H. A. (1969), The sciences of the artificial, M.I.T. Press, Cambridge,.

Sosa, M. E., Eppinger, S. D. and Rowles, C. M. (2004), "The misalignment of product architecture and organizational structure in complex product development". Management Science, Vol. 50, pp. 1674-1689.

Teece, D. J. (2007), "Explicating dynamic capabilities: The nature and microfoundations of (sustainable) enterprise performance". Strategic Management Journal, Vol. 28, pp. 1319-1350.

Teece, D. J., Pisano, G. and Shuen, A. (1997), "Dynamic capabilities and strategic management". Strategic Management Journal, Vol. 18, pp. 509-533.

Tushman, M. L. and O’reilly, C. A. (2006), Winning Through Innovation: A Practical Guide to Leading Organizational Change and Renewal, Harvard Business Review Press.

Waterman, R. H., Peters, T. J. and Phillips, J. R. (1980), “Structure is not organization”. Business Horizons, Vol. 23, pp. 14-26.

Weick, K. E. (2004), "Rethinking organizational design”. In: Boland, R. J. and Collopy, F. (eds.) Managing as Designing. Stanford: Stanford Business Books.

Weick, K. E., Sutcliffe, K. M. and Obstfeld, D. (2005), “Organizing and the process of sensemaking”. Organization Science, Vol. 16, pp. 409-421. 